\title{
Selection of Materials for Building Desalination Plants
}

\author{
Michael Schorr ${ }^{*}$, Benjamín Valdez-Salas, Ernesto Beltran-Partida, Jorge Salvador-Carlos \\ Department of Corrosion and Advanced Materials, Engineering Institute of Baja California, Mexicali, Mexico \\ Email address: \\ mschorr2000@yahoo.com (M. Schorr), benval@uabc.edu.mx (B. Valdez-Salas), beltrane@uabc.edu.mx (E. Beltran-Partida), \\ jsalvador@uabc.edu.mx (J. Salvador-Carlos) \\ *Corresponding author
}

\section{To cite this article:}

Michael Schorr, Benjamín Valdez-Salas, Ernesto Beltran-Partida, Jorge Salvador-Carlos. Selection of Materials for Building Desalination Plants. International Journal of Mineral Processing and Extractive Metallurgy. vol. 4, No. 3, 2019, pp. 51-57.

doi: 10.11648/j.ijmpem.20190403.11

Received: August 29, 2019; Accepted: September 16, 2019; Published: October 12, 2019

\begin{abstract}
The primordial method to prevent, avoid and/or mitigate the deterioration of desalination plants (DP) materials is the selection of chemical and mechanical resistant materials to the DP operation conditions. Three different types of saline waters (SW) are treated in DPs: sea water, brackish water (BW) and brines, a byproduct that showed be disposed to avoid ecological problems. A DP is a complex, organized structure managing physicochemical processes: compression, filtration, evaporation, condensation, and circulation, involve diverse equipment, e.g. pumps, pipelines, turbines, heat exchangers, deaerators, storage tanks, valves, control and flow instruments. Metallic, plastic and composite materials are applied for the manufacture of these equipments. The surface of DP equipment should be kept clean and smooth applying sanitation regulation to prevent sealing and fouling difficulties. It is convenient to attach a corrosion technician at a DP to manage a corrosion laboratory, to expose corrosion test specimens of new materials and to control the corrosive factors of the DP fluids, to avoid expensive damaging corrosion occurrences. Modern DPs are built from correctly selected CRA and CRM. Application of recognized and approved technology of corrosion protection and control should provide prolonged equipment service life and freedom form corrosion. Correct operation and maintenance of a DP will assure the efficiency and economic profitability of the desalination industry (DI) rand provide prolonged equipment service life and freedom from corrosion.
\end{abstract}

Keywords: Desalination Plant, Desalination Processes, Saline Waters, Materials, Corrosion

\section{Introduction}

The sustainability and prosperity of the ancient civilizations of China, Egypt, Babylonia, Phoenicia, Persia, Greece and Roma were based on the extensive use of water for human consumption, crop irrigation, canal navigation and energy generation. Today, the worldwide scarcity of water and clean energy constitutes central and critical problems for the whole humankind [1-3]. This situation is aggravated as industrial, agricultural and municipal effluents reach the water bodies, or the coastal seawater used as feed for DPs. All these problems are linked to the actual, natural and anthropogenic changes of climate, global warming and greenhouse gas emissions, all interrelated phenomena that affect our planet.

In order to avoid damage to its facilities and equipment, the DI invest considerable efforts to deal with these changes, in particular with extreme events such as torrential rains, devastating floods, dry seasons with devouring fires, as well as with extended spells of cold weather with freezing temperatures.

Recently, NACE International launched a new service: Corrosion Research, facilitating corrosion mitigation for companies, government bodies, research organizations, universities, professional associations, seeking to solve corrosion issues [4-7].

In the next years the global demand of clean municipal and industrial water; the water required for food processing and production, and the water needed in the energy sector, will increase considerably, according to a World of Bank report. This report informs that 1.6 billion people are subject to water scarcity. Modern desalination technology, to reduce potable water storage in the future, is the true response to this critical situation [8]. 


\section{Desalination Industry}

Desalination, transforming SW into potable water, did not start yesterday; it is known from biblical times. The people of Israel, wandering in the Sinai desert was desperately searching for water, and then their leader Moses found bitter water. In an act of magic, threw a piece of wood into the water that become fresh water (Exodus 15: 22-25). Is this an ancient practice for water treatment, whose procedure has been lost in the eons of history?

The U.S. established the Office of Water Research and Technology and in 1952 the Congress passed "The Saline Water Act" to promote the DI, particularly in the southeast arid, desertic regions.

Nowadays, the DI is spread out in continents: America, Europe, Asia, Africa and Australia, in many countries but for the sake of brevity the DI is presented only in Mexico, USA and Israel. These nations possess a strong economy, a modern agriculture; a high-tech industry and a dynamic society. These countries comprehend vast regions of dry arid, desertic climate, high temperatures, low level of rains, and brackish ground water, therefore they are erecting DPs.

The DI is in the middle of an expansion and modernization program designed to construct more efficient and larger DPs that will reduce production costs. The maintenance of its infrastructure assets requires a robust understanding of the integration, induced by variations in humidity, temperature, solar radiation, drought and pluvial precipitation mainly during extreme events [5].

The planning and design of a new DP include three central activities: a decision on a desalination process suitable to the available SW, to the region climate and plan site characteristics. In the section for the construction of the infrastructure, the structures and installations and for the fabrication of the equipment and machinery are presented.

Mexico is a vast, maritime country, surrounded by seas and oceans, having a complicated distribution of water resources, with plenty of water in the southeast region whereas in the northwest there is water scarcity, e.g. the State of Baja California. Extraction of underground water in areas near to seacoast causes saline contamination of the underground aquifer. The cities of Rosarito, Tijuana, Ensenada and Hermosillo had installed some DPs and other huge desalination projects are in the planning stage.

The National Autonomous University of Mexico (UNAM) has created a Project for Multidisciplinary Investigation for Leadership and Academic Improvement (its Spanish acronym IMPULSA), with SW desalination as its central activity, applying renewable sources of energy. IMPULSA maintains cooperation links with desalination institutes in Spain, Israel, and USA [8].

The southwest U.S. states constitute a dry, desertic region, affected by frequent droughts; then supplies of clean water become scarce. To overcome this crucial situation, the largest DP in the Western Hemisphere, applying the Reverse Osmosis (SWRO) process, was built at Carlsbad, CA, that will provide $200000 \mathrm{~m}^{3} /$ day of fresh water to the San Diego County. The plan provides fresh water to 300000 people; a mile $(1.6 \mathrm{Km})$ pipe of a composite GFRP was employed for the water transport. This DP was the result of international cooperation, with American, Israeli and Spanish desalination enterprises covering the financial, technical, equipment, and engineering materials aspects of this special DP [9].

The DI started in Israel with construction of DPs around 1960, establishing cooperation between Mekorot-National Water Company and IDE-Technologies, the national desalination enterprise, installing thermal DP in several parts of the country, in particular in the southern arid region; reaching the Red Sea [10-12].

Today, IDE-Technologies is considered as one of the prominent desalination companies developing, designing and erecting DPs worldwide following the BOT-Built-OperateTranfer system. [13].

From 1998 the Israel Desalination Society (IDS), holds yearly conference on desalination science, technology and engineering, including corrosion management of DPs. The European Desalination Society (EDS) and its desalination journals, organize conferences, courses and congresses over the world, including prevention and avoidance of corrosion, scaling and fouling.

Table 1. Israel desalination plants.

\begin{tabular}{|c|c|c|c|}
\hline Water cost $\left(\mathrm{NIS} / \mathrm{m}^{3}\right)$ & Location & Capacity (million $\mathrm{m}^{3} /$ year) & Opened \\
\hline 2.60 & Ashkelon & 120 (as of 2010$)$ & August 2005 \\
\hline 2.90 & Palmachim & 45 & May 2007 \\
\hline 2.60 & Hadera & 127 & December 2009 \\
\hline $2.01-2.19$ & Soreq & 150 (expansion up to 300 approved) & 2013 \\
\hline 2.40 & Ashdod & 100 (expansion up to 150 possible) & September 2014 \\
\hline
\end{tabular}

\section{Saline Waters}

As the world's population grows, fresh water resources are getting increasingly scarce. Nevertheless, there is plenty of water around, in oceans and seas, but they are salty, not suitable for human consumption, therefore driving a global boom for the desalination industry $[14,15]$.

The significant difference in chemical composition between fresh and SW determines the diverse corrosion performance of the engineering materials utilized in the sectors of a DP (Table 2).

The U.S. Geological Service (USGS) groups SW in three salinity categories: low 1000 to $3000 \mathrm{ppm}$; moderate, 3000 to $10,000 \mathrm{ppm}$, and high, 10,000 to $35,000 \mathrm{ppm}$. Some SW are slightly alkaline due to presence of carbonate, bicarbonate and hydroxide compounds. 
Table 2. Chemical composition of fresh and saline waters.

\begin{tabular}{|c|c|c|c|c|c|c|c|c|c|c|}
\hline Water & $\mathrm{Na}^{+}$ & $\mathbf{K}^{+}$ & $\mathrm{Mg}^{2+}$ & $\mathrm{Ca}^{2+}$ & $\mathrm{Cl}^{-}$ & $\mathrm{HCO}_{3}^{-}$ & $\mathrm{SO}_{4}^{2-}$ & $\mathrm{SiO}_{2}$ & $\mathbf{E C}^{\mathbf{a}}$ & TDS $^{\mathrm{a}}$ \\
\hline Fresh $(\mathrm{mg} / \mathrm{l})$ & 6.3 & 2.3 & 4.1 & 15.0 & 7.8 & 58.4 & 11.2 & & $2-5$ & 150 \\
\hline Sea $(g / 1)$ & 107 & 0.2 & 1.3 & 0.41 & 19.3 & 0.14 & 2.71 & 10 & $50-60$ & 35 \\
\hline Brackish (mg/l) & 820 & 47 & 198 & 315 & 1816 & 292 & 614 & 29 & 5.9 & 4100 \\
\hline Dead Sea $(g / l)$ & 36 & 7.8 & 45.9 & 17.6 & 67 & & & 200 & & 250 \\
\hline
\end{tabular}

The oxidation reduction potential (ORP) of water measures the ratio of the activities of the oxidized to the reduced species present in water. This value (in volts $\mathrm{V}$ ) is determined applying the ASTM standard D1498 [15].

BW have ORP (also called redox potential) values in the range 0.10 to $0.60 \mathrm{~V}$ but when they are contaminated with $\mathrm{H}_{2} \mathrm{~S}$, a weak acid, the values decrease to electronegative values: -0.28 to -0.50 volts. These ORP values influence the corrosion behavior of BWs [16].

SW are classified into three categories: seawater, brackish water (BW) and brines. Their main characteristics of SW, from the corrosion point of view, are salinity, chlorinity and dissolved oxygen (DO), which ranges from $4 \mathrm{mg} / 1$ to $8 \mathrm{mg} / \mathrm{l}$ depending on temperature, depth and the volume of river's fresh water discharging into them. Seawater is slightly alkaline, having a $\mathrm{pH} 8.0$ but it decreases when seawater absorbs $\mathrm{CO}_{2}$ from the atmosphere, particularly in coastal areas where power stations burning fossil fuels are located. The following equilibrium is established:

$$
\mathrm{CO}_{2}+\mathrm{H}_{2} \mathrm{O} \rightarrow \mathrm{H}_{2} \mathrm{CO}_{3} \rightarrow \mathrm{HCO}_{3}^{-}+\mathrm{H}^{+}
$$

The vast deserts and arid regions of the world occupy about $40 \%$ of this planet lands, with scarce rains, high summer and low winter temperatures and salty waters. In some places BWs are feed for desalination in DPs.

BWs contain chloride, carbonate and sulfate salts with a total dissolved solid (TDS) of $4.1 \mathrm{~g} / 1$ (Table 2). Additionally, they include dissolved gases, ppm: $\mathrm{H}_{2} \mathrm{~S}, 1$ to $6 ; \mathrm{O}_{2} 1$ to 3 and $\mathrm{CO}_{2} 10$ to 40. A high level of $\mathrm{H}_{2} \mathrm{~S}$ implies a low content of dissolved oxygen (DO) since it oxidizes $\mathrm{H}_{2} \mathrm{~S}$ to elemental sulfur:

$$
\mathrm{H}_{2} \mathrm{~S}+0.5 \mathrm{O}_{2} \rightarrow \mathrm{S}^{0}+\mathrm{H}_{2} \mathrm{O}
$$

In the last decades BW are being used, after a pretreatment and $\mathrm{H}_{2} \mathrm{~S}$ removal, as feed water for desalination plants. $\mathrm{H}_{2} \mathrm{~S}$ is responsible for lowering the $\mathrm{pH}$ of $\mathrm{BW}$ to an acidic corrosion mechanism with cathodic depolarization and increased anodic dissolution.

Brines, natural and industrial are aqueous, concentrated solutions of salts, mainly $\mathrm{NaCl}$, with a salt content of $3.5 \%$ up to $26 \%$, a saturated solution such as waters of the Great Salt Lake, Utah, U.S. and the Dead Sea, Jordan, Israel (Table 2).

Brine is a byproduct of DPs; that is disposed conducting it back into the sea, near the coast, or into solar evaporation ponds and probably, for industrial application of their salt. On the other hand, brine disposal constitutes and ecological issue since it may affect vegetable and animal life, therefore these ponds are lined with flexible, impermeable rubber or plastic sheets to avoid infiltration into the aquifer. Brines are disposed in accordance with the environmental regulations of the countries involved.

\section{Desalination Processes and Equipment}

It should be clear that there is no universal desalination process; every type of SW requires a process adapted to its physicochemical characteristic and performance. The DPs are feed with seawater, containing $35 \mathrm{~g} / 1$ of TDS or BW with TDS in the range 2 to $5 \mathrm{~g} / \mathrm{l}$, taken from briny wells infiltrated by seawater. Many DPs are located in desertic, arid regions with a harsh climate and limited rainfall. About one-fifth of the DPs operate in the Middle East with Saudi Arabia, producing half of the world desalted water [17-19].

A practical application of desalination techniques is the production of fresh water on ships, islands, and in the coastal regions of arid countries, such as Baja California, Mexico and North Africa countries.

Two main desalination technologies (membrane and thermal) are implemented worldwide. The processes fundamentals and their physicochemical characteristics are shortly presented in Table 3 and Table 4.

Table 3. Membrane and thermal desalination processes.

\begin{tabular}{ll}
\hline Process & Characteristics \\
\hline Membrane & \\
Reverse osmosis (RO) & Pressure is applied to the SW forcing in through a semipermeable plastic membrane that separates brine form water. \\
Thermal & Hadera \\
Multistage flash distillation (MFD) & SW is heated: the pressure is lowered in several stages, so the water flashes into steam, to be cooled. \\
Multi-effect distillation (MED) & Low pressure steam, 60 C, is handled in a train of evaporative condensers (effects) with heat rejection condensers. \\
Mechanical vapor compression (MVC) & Distillation is affected by an electrically driven centrifugal compressor mounted on the evaporator \\
\hline
\end{tabular}

Table 4. Equipment for desalination plants.

\begin{tabular}{ll}
\hline Mechanical equipment & Thermal equipment \\
\hline Pipes, tubes and ducts & Evaporators \\
Saline water pumps, vertical and centrifugal & Vapor condensers, diesel engines \\
\hline
\end{tabular}




\begin{tabular}{ll}
\hline Mechanical equipment & Thermal equipment \\
\hline Valves, diverse types & Flash cambers \\
Gasketed plate and frame HE & Demisters \\
Fittings and flanges & Condensers \\
Steam and gas turbines & Deaerators \\
Compressors & Chlorinators \\
Control and flow & Storage tanks \\
Instrumentation & \\
\hline
\end{tabular}

Membrane separation process e.g. Reverse Osmosis (RO). Under high pressure the water molecules contained in seawater pass through a selective membrane while the dissolved salt ions do not pass through the membrane. Some RO membranes are made from high-grade polymeric PVDF material to form a hollow fiber membrane that is very durable and less prone to breakage. Special membrane incorporate a brush layer of hydrophilic polymer chain anchored to the membrane surface, which blocks foulants such as bacteria, mineral crystals and proteins from adhering to the membrane. It also resists mineral scaling by preventing its nucleating on the surface. Others membranes are made from polymers specially developed and manufactured to serve in DPs. RO desalting devices are used also to upgrade the quality of industrial water (Figure 1).

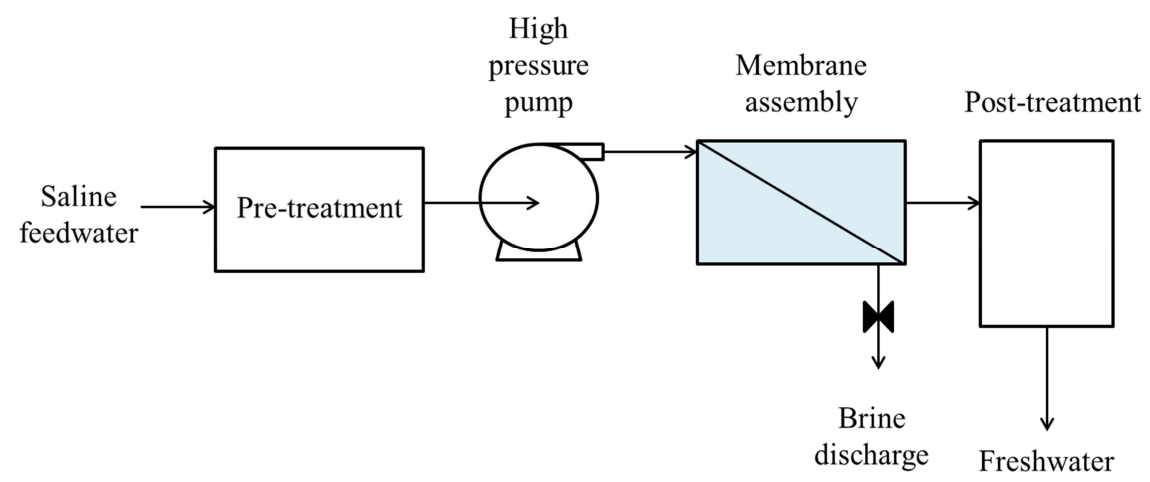

Figure 1. Diagram of desalination process by reverse osmosis.

The thermal processes are based on improved distillation, evaporation and condensation technologies with the aim to save energy and to obtain fresh water with low level of TDS and at a low cost operation. In general, the thermal processes are more expensive than RO but distillation produces pure water independent of the quality and salinity of the feed water. The cost of desalting brackish ground water is generally less than the cost of desalting seawater due to a lower TDS content [20].

Operation of DPs consumes large amounts of electricity, obtained from power stations that burn fossil fuels: natural gas, coal or petroleum derivatives. Therefore, some scientists, researchers and technicians recommend to consider the possibility of applying solar energy for converting SW into potable water.

Renewable energy technologies, e.g. wind, solar and geothermal show great promise for water desalination, in particular in arid regions. Solar energy is applied either to generate the heat needed for desalination and/or to generate electricity, to provide for the operation of the DPs.

The port and town of Almeria was founded in the past by the Phoenicians, during their colonization enterprise along the Mediterranean seacoast. Almeria is located in the southwest of the Iberian Peninsula, an area with the most hours of sunshine and lowest rainfall in Europa. It is the only desertic, arid region of Europe, suitable for the good use of solar energy for desalination of seawater [21-23].

\section{Maintenance Avoids Plant Deterioration}

Two modes of maintenance technology are managed in industrial, chemical plants, including DPs: preventive and routine maintenance, sometimes called scheduled or corrective. Preventive maintenance work deals with the electrical, mechanical and control technology, which prevents a DP shutdown Routine maintenance locates, repairs or replaces damaged equipment in cooperation with the Original Equipment Manufacturer (OEM), to ensure a continuous and correct flow of the DP [24].

The maintenance engineers and technicians of DPs are busy with one central, crucial problem that damage the material and equipment and disturbs the plan operation: corrosion. Sometimes, scaling and biofouling increases the corrosion activity, when it occurs under the scale deposits and fouling secretions, with salty or acidic substances [25-27].

There are deterioration phenomena; their extent and intensity depend on the chemical and biological characteristics of the feed SW and the DP fluids and streams (stagnant or flowing) and on the mechanical and thermal conditions of DP operation. These operational parameters, e.g. $\mathrm{pH}$, flow regime and velocity, temperatures and pressures should be monitored and recorded continuously. 
To avoid atmospheric corrosion, the DPs installations and structures should be protected with industrials paints and coatings, in particular in tropical areas or near seacoast close to large city or port, with high salinity and humidity and fine particles of airborne chloride salts.

\section{Selection of Engineering Materials}

The degradation of engineering materials constitutes a significant economic, environmental and safety risk. Practical methods that eliminate corrosion include selection of suitable CRA (in case of metallic) and CRM (in case of plastics and composites). These engineering materials will not react with the DP fluids. The technical processes of selection are divided into three stages $[28,29]$.

a) Analysis of the requirements and collection of the relevant information about the conditions imposed by the desalination process and the corrosion resistance required by the desalination equipment.

b) Selection and evaluation of candidate materials by screening of the information collected in the first stage. The suitability of possible materials, based on their availability, strength, ease of fabrication, maintenance, safety and cost, is critically evaluated.

c) According to these data the most appropriate material should be chosen, to perform its function for a reasonable period at a reasonable cost.

The final decision should be a compromise between technological and economic factors. Sometimes it is more convenient to use a high priced material that provides a troublefree service than to use a lower-priced material that require frequent maintenance or replacement.

Protection against deterioration is achieved by application of coatings and linings that act as a nonreactive barrier between the environment and the material to be protected.

While coatings usually are applied as a liquid or a powder or deposited form a solution, linings are applied as solid materials such as sheets of rubber. Some linings are in the form of polyester or epoxy resins reinforced with glass flakes or fibers.

Paints are complex mixtures that are applied as a liquid film on a surface and harden to a solid protective coating. To protect against corrosion, a paint coating should exhibit good cohesion and adhesion, low permeability to air and moisture, and high chemical resistance.

To ensure the success of a coating, the surface of the material to be protected should be properly cleaned before application of the coating. Suitable chemical and mechanical pretreatments are specified in codes of practice issued by the Steel Structures Paint Council (SSPC), the Swedish Institute of Standard (SIS), National Association of Corrosion Engineers (NACE), and other technical organizations.

\section{Corrosion Resistance Materials (CRM)}

One of the main activities in the development of a DP, particularly during the design stage is the selection of CRM, which assure a continuous efficient operation without shutdowns, a low expense in maintenance and in replacement of corroded equipment.

The central aim of this section is to assess the CRMs considered as suitable for DPs. Moreover, cases of corrosion occurring in the diverse sectors of a DP are presented as a warning and alert for DP designers and constructors, to prevent such occurrences.

The numerous engineering materials listed are classified into three large groups: metallic alloys, plastics include polymers, rubbers and elastomers and composites.

The CRAs are associated in several groups: general alloys, carbon steel, aluminum, copper, Ni-based-alloys and $\mathrm{Ti}$ alloys, (Table 5), all identified by the Unified Numbering System (UNS).

Table 5. Corrosion-resistant materials used in desalination plants.

\begin{tabular}{ll}
\hline Alloys, UNS & Chemical composition (\%) \\
\hline G 10080 & Fe-C (ASTM A 242, AISI 1080) \\
A 95052 & Al-2.5Mg \\
C 70600 & 90Cu-10Ni \\
S 30400 & Fe-18Cr-10Ni \\
S 31600 & Fe-18Cr-12Ni-3Mo \\
S 08028 & Fe-27Cr-31Ni-3Mo \\
S 31700 & Fe-18Cr-8Ni-3Mo \\
S 31254 & Fe-20Cr-18Ni-6.1Mo \\
S 31803 & Fe-25Cr-5.7Ni-2.8Mo \\
N 06035 & 2Fe-33Cr-58Ni-8.1Mo \\
N 08904 & Fe-20Cr-25Ni-4.5Mo \\
N 06030 & Fe-20Cr-5.5Mo \\
R 52400 & Ti-0.1Pd \\
Plastic & \\
PVC & Polyvinylchloride \\
PE & Polyethylene \\
PVDF & Polyvinylidene fluoride \\
Rubber & Natural and synthetic \\
Composite & \\
RC & Steel reinforced concrete \\
FGRP & Fiberglass-reinforced plyester \\
\hline
\end{tabular}

Carbon steel is the main structural alloy for a DP, but also for water storage and conveying ducts. It is preferred due to its mechanical properties, easy handling and welding. Its limited corrosion resistance is improved by painting and coating and for huge equipment by cathodic protection (CP).

Some water treated in carbon steel and cast iron equipment acquire a red-brown tint due to the dissolution and/or suspension of iron corrosion products e.g. hematite $\mathrm{Fe}_{2} \mathrm{O}_{3} \mathrm{XH}_{2} \mathrm{O}$. These waters are called "rouge" water; the corrosion products should be separated by filtration.

$\mathrm{Al} / 2.5 \mathrm{Mg}$ tubes are used in thermal desalination processes for the fabrication of huge heat exchangers to cool water vapor with sea-water. The corrosion resistance of $\mathrm{Al}$ alloys derives from the formation of a passive layer of $\mathrm{Al}_{2} \mathrm{O}_{3}$. In a multi-effect desalination (MED) process the huge heatexchanger is made from Al alloys tubes and the steel evaporator body is coated with epoxy resin.

$\mathrm{Cu}-\mathrm{Ni}, \mathrm{Cu}-\mathrm{Sn}$ (bronze) and $\mathrm{Cu}-\mathrm{Zn}$ (brass) alloys are useful in DPs for pumps and pipes to transport seawater and other waters circulation, particularly for heating and evaporating 
process for seawater and to obtain distillate water for steam generators and for potable water. The green, blue, brown corrosion products are $\mathrm{Cu}$-salts that do not provide protection and should be removed periodically by chemical cleaning.

Diverse stainless steels (SS) treat fresh and SW, with different concentration of $\mathrm{NaCl}$, at ambient and high temperature, in membrane and thermal DPs, worldwide. The formation of adhered, thin passive layers of oxides, in the presence of air and moisture, assures their corrosion resistance.

$\mathrm{Ni}$-alloys, with $\mathrm{Ni}$ concentrations increasing from $5.7 \%$ to $58 \%$ find important applications in thermal DP for highpressure pumps, heat-exchanger and brine concentrator at elevated temperatures.

As a rule, Al-Mg alloys serve in heat transferring equipment operations but when the DP processes highly corrosive BWs, geothermal brines, waters produce form oil fields; tubes and plates heat exchangers are fabricated form Ti or Ti-Pd alloys, with augmented corrosion resistance.

Plastic engineering materials, derived from petroleum components are polymerized and converted into solid materials with the form of sheets, plates, tubes, pipes, etc. for the manufacture of corrosion-resistant equipment. They comprise thermoplastics and thermosets, natural and synthetic rubbers (Table 5). Rigid plastics such as PVC, PE, $\mathrm{PP}$ are utilized for the construction of pipelines and storage tanks. Some carbon steel tanks are internally lined with flexible, sheets of rubber or plasticized PVC. Rubbers are also employed as packing seals for valves, pipelines, heat exchangers and O-rings of pumps.

Composites are produced from two constituents: a matrix and reinforcing materials. Several composites include a metal matrix and carbides and nitrides reinforcements; other composites are formed by a resin matrix and glass fiber or carbon fiber as reinforcement. Concrete, a useful material has a mineral matrix and steel rods as reinforcement.

Composites are used for manufacture of pipes, pumps and fittings for conveyance of water in DPs, for storage containers of waters and fuels and for canals to conduct brines and waste water. Equipment deterioration happens by defective fabrication, by delamination or by shock impact. Steel reinforced concrete is used to construct the base of containers for huge tanks for liquids storage and for drainage channels. Concrete is attacked by corrosive brines, sometimes the concrete is protected by special paints or flexible rubber sheets.

\section{Conclusions and Recommendations}

A DP, a dynamic system, operates under the constant risk of corrosion, due to the corrosive fluids being handled and the severe mechanical conditions. Therefore, the plant personal should be trained and acquainted with the corrosive factors, mechanism and treatments involved in the multiple corrosion events.

Corrosion resistance is the essential property to be considered when selecting construction materials, in the DP design and election stages, from the ample offer of the materials market: metallic, plastics and composites. SS is today the favorite CRA for DPs. The choiced CRM should perform safely, at a reasonable cost and for a long-live service without maintenance problems.

The surface of DP equipment and machinery should be keep clean and smooth, applying sanitation regulation to prevent deposition of mineral scaling and grow of biofouling. Mechanical-chemical cleaning technology should be implemented to remove scaling and fouling.

It is convenient to attach a corrosion technician at a DP to manage a corrosion laboratory, to expose corrosion test specimens of new materials and to control the corrosive factors of the DP fluids, to avoid expensive damaging corrosion occurrences.

Modern DPs are built from correctly selected CRA and CRM. Application of recognized and approved technology of corrosion protection and control should provide prolonged equipment service life and freedom form corrosion.

\section{References}

[1] B. Chalker, "NACE international launches corrosion research consortia" vol. 59, p. 52.

[2] G. A. Jacobson, "NACE international expert round-table, Material Performance", 2018, vol 57, p. 36-48.

[3] R. Hummel, "Alternative futures for corrosion and degradation research", Potomac institute press, 2014.

[4] World bank report, high and dry: climate change, Water and the economy, year? https://www.worldbank.org/en/topic/water/publication/highand-dry-climate-change-water-and-the-economy

[5] B. Valdez and M. Schorr, "Relationship of corrosion with global warming and climate change", Corr. Sci. Tech., 2010, vol. 45, doi: 10.1179/147842210x12635511700839.

[6] B. Valdez and M. Schorr, "Desalination, trends and technologies", Desalination and Water treatment, vol. 42, pp. 347-348, doi: 10.1080/19443994.2012.683289.

[7] R. M. Latanision, "Corrosion science, corrosion engineering, and advanced technologies", Corrosion, 1995, vol. 51, pp. 270-283.

[8] S. M. Alcocer and G. Hirart, "An applied research program on water desalination with renewable energies", American journal of environmental sciences, 2008, vol. 4, pp. 204211.

[9] The Carlsbad desalination project, www.carlsbad-desal.com, 2014.

[10] A. Livnat, "Desalination in Israel: emerging key component in the regional water balance formula", 1994, vol. 99, pp. 299327.

[11] A. Tenne, "The master plan for desalination in Israel", Israel water authority, 2020, www.water.gov.il

[12] Y. Dreizin, “Ashkelon seawater desalination project-offtaker's self-costs, supplied water costs, total costs and benefits". Desalination, 2006, pp. 104-116. 
[13] A. Ophir, F. Lokiec, "Advanced MED process for most economical seawater desalination", Desalination, 2005, vol. 182, pp. 187-198.

[14] V. S. Frenkel, "Seawater desalination: trends and technologies", Desalination, trends and technologies, 2011, pp. 121-128.

[15] J. Charrach, M. Schorr, and E. Weintraub, "Corrosion and scaling behavior in dead sea basin saline waters", Corrosion reviews, 1990, vol. 9 .

[16] M. El-Naas, "Reject brine management", Desalination, trends and technologies, 2011, doi: 10.5772/13706.

[17] V. Belessiotis, S. A. Kalogirou and E. Delyannis, "Desalination methods and technologies - water and energy", Thermal solar desalination, 2016, pp. 1-19.

[18] A. Malik, I. Andijani, M. Mobin, S. Al-Fozan, F. Al-Muaili and M. Al-Haijiri, "An overview of the localized corrosión problems in seawater desalination plants-some recent case studies", Desalination and water treatment, 2010, vol. 20, pp. 22-34.

[19] A. U. Malik, T. L. Prakash and I. Andijani, "Failure evaluation in desalination-some case studies" Desalination and water, sciences, 1995, pp. 116-1132.

[20] M. Schorr, B. Valdez, J. Ocampo and A. Eliezer, "Corrosion control in the desalination industry" Desalination, trends and technologies, 2011.
[21] CIEMAT-Center of investigations in energy, environments and technologies, "Desalination with solar energy", www.desaline.com/almeria

[22] The solar thermal desalination project/Almeria solar platform, www.desalination.biz

[23] B. Chaouachi, "Solar desalination", Desalination, trends and technologies, 2011, doi: 10.5772/13909.

[24] Desalination and water resources plant operation maintenance and management, 2010, ISBN 978-1-84826-884-5.

[25] A. A. Al-Karaghouli and L. L. Kazmerski, "Renewable energy opportunities in water desalination", Desalination, trends and technologies, 2010.

[26] M. Goosen, H. Mahmoudi, N. Ghaffour and S. S. Sablani, "Application of renewable energies for water desalination", Desalination, trends and technologies, 2011.

[27] N. Voutchkov, "Desalination engineering: planning and design”, 2014, ISBN 978-0071777155.

[28] A. Malik, S. Al-Forzan "Corrosion and materials selection in MSF desalination plants", Corrosion reviews, 2011, vol. 29.

[29] A. U. Malik, I. N. Andijani, M. Mobin and S. Ahmad, "Corrosion behavior of materials in RO water containing 250350 ppm chloride", Desalination, 2006, vol. 196, pp. 149-159. 